\title{
The Brigade Battle Captain - A Prototype Training Product
}

\author{
Richard L. Wampler and James Centric \\ BDM International, Inc. \\ Margaret S. Salter \\ U.S. Army Research Institute
}

\author{
Infantry Forces Research Unit \\ Scott E. Graham, Chief
}

U.S. Army Research Institute for the Behavioral and Social Sciences 5001 Eisenhower Avenue, Alexandria, Virginia 22333-5600

June 1998

Army Project Number

20262785A790

\section{Personnel Systems and Performance Technology}

Approved for public release; distribution is unlimited. 